\title{
Axitinib-Induced Hypothyroidism as a Predictor of Long-Term Survival in Patients with Metastatic Renal Cell Carcinoma
}

\author{
Shinya Takada ${ }^{a}$ Hirokazu Hashishita $^{a}$ Satoshi Nagamori ${ }^{b}$ Masayuki Endo ${ }^{a}$ \\ a Department of Pharmacy, National Hospital Organization Hokkaido Cancer Center, Sapporo, Japan; \\ ${ }^{b}$ Department of Urology, National Hospital Organization Hokkaido Cancer Center, Sapporo, Japan
}

\section{Keywords}

Metastatic renal cell carcinoma $\cdot$ Axitinib $\cdot$ Hypothyroidism

\begin{abstract}
Background: The side effects of sunitinib, namely onset of hypertension and hypothyroidism, have been reported to be predictive biomarkers of treatment efficacy. However, the relationship between hypothyroidism and prolongation of survival in treatment with axitinib, a drug similar to sunitinib, has not yet been reported. Objective: In this study, we examined the relationship between the onset of hypothyroidism caused by axitinib and overall survival (OS) and progressionfree survival (PFS). Methods: In this retrospective study, 44 Japanese patients, including 30 men and 14 women, were enrolled. The average age of subjects in this study was 67 years. Results: During treatment, $68 \%$ of patients developed hypothyroidism, with an average peak thyroid-stimulating hormone (TSH) value of $15.7 \mathrm{mlU} / \mathrm{L}$. Patients with $\mathrm{TSH}>4 \mathrm{mIU} / \mathrm{L}$ and required thyroid hormone regulation with
\end{abstract}

\section{KARGER}

(c) 2019 S. Karger AG, Basel

E-Mail karger@karger.com

www.karger.com/uin levothyroxine had prolonged PFS (11.1 vs. 3.5 months; $p=$ 0.002 ) and OS ( 26.4 vs. 15.6 months; $p=0.02$ ). Hypothyroidism was found to be a significant side effect of axitinib in patients with metastatic renal cell carcinoma (mRCC). Patients with hypothyroidism had significantly longer PFS and OS. Conclusion: Our findings indicate that hypothyroidism may be a predictive marker of therapeutic effect of axitinib against $\mathrm{mRCC}$.

(c) 2019 S. Karger AG, Basel

\section{Introduction}

Metastatic renal cell carcinoma (mRCC) accounts for $2-3 \%$ of all adult malignancies and is the seventh common cancer in men and the ninth most common cancer in women. The incidence of $\mathrm{mRCC}$ has increased in the past few years, contributing to increase in mortality rate [1]. Axitinib is a tyrosine kinase inhibitor (TKI) of vascular endothelial growth factor receptors (VEGFR) 1,2, and 
3 [2]. A randomized phase III study (the AXIS trial) compared axitinib and sorafenib, which are VEGF-targeting agents, as a second-line treatment of mRCC [3]. Although systemic therapy is provided for patients with mRCC, surgical resection of primary tumor is recommended. mRCC is resistant to chemotherapy and radiation. Initially, around $20-25 \%$ of patients are refractory to treatment, while others tend to show some response. However, resistance is easily acquired. Until recently, cytokine treatment (e.g., interferon-alpha or interleukin-2) was performed for mRCC. Ever since cytokine therapy was switched to angiogenesis inhibition therapy, treatment strategy has changed dramatically. Angiogenesis is a key element in tumor growth and metastasis, and VEGF is an important factor required for angiogenesis. Angiogenesis inhibitors have become the standard of care for advanced and/or mRCC. Thus, VEGFR inhibitors have emerged as a new treatment strategy [3-8]. Hypertension, proteinuria, and hypothyroidism have been known to inhibit VEGF pathway. In patients with mRCC, hypertension due to sunitinib has been reported as a predictive marker [9]. In patients with lung cancer, the onset of hypertension has been reported to correlate with improvement of overall survival (OS) in patients receiving anti-VEGF monoclonal antibody (e.g., bevacizumab). To investigate the relationship between on-target effects and prolongation of survival, we investigated 44 patients with mRCC who received axitinib treatment. On-target effects occur because of primary pharmacological effects of a drug. In this study, we evaluated the effect of hypothyroidism, a marked side effect of axitinib, on prolongation of survival in patients with mRCC. Our results indicated that thyroid function assessment could be an important and effective marker when using axitinib for mRCC treatment.

\section{Patients and Methods}

This single center, retrospective study included patients who received axitinib at Hokkaido Cancer Center Hospital in Japan. A total of 44 Japanese patients were enrolled in this study between September 2012 and August 2018. The main inclusion criteria were as follows: patients who used axitinib as a secondary TKI; patients who used axitinib for more than 1 month; and patients whose side effects could be retrieved from clinical records. The exclusion criteria were as follows: patients who used axitinib as the primary TKI; patients who underwent thyroid disease treatment at the start of axitinib; and patients in whom thyroid function was difficult to control using levothyroxine. Axitinib was administered orally at a starting dose of $5 \mathrm{mg}$ twice daily. The doses were adjusted based on hematological toxicity and nonhematological toxicity adverse events, according to the manufacture's recommenda-
Table 1. Baseline patient characteristics

\begin{tabular}{ll}
\hline Characteristic & $\begin{array}{l}\text { All patients }(n=44) \\
\text { number of patients }\end{array}$ \\
\hline $\begin{array}{ll}\text { Age, years, median (IQR) } \\
\text { Gender, male/female }\end{array}$ & $67(64-73)$ \\
Prior number of chemotherapy regimen & $30 / 14$ \\
$33 / 8 / 3$ \\
\hline
\end{tabular}

$\mathrm{IQR}$, interquartile range.

tions manual. The serum concentrations of thyroid-stimulating hormone (TSH) were obtained at baseline and every 4 weeks. The thyroid function test was performed for 6 months. The range of facility reference values for TSH was $0.4-3.5 \mu \mathrm{IU} / \mathrm{mL}$. In this study, hypothyroidism was defined as institutional standard value of $\mathrm{TSH}>3.5 \mu \mathrm{IU} / \mathrm{mL}$, along with clinical symptoms (e.g., fatigue) and requirement of levothyroxine administration. The thyroid function was checked before the start of axitinib and when the patient visited the hospital.

\section{Statistical Analysis}

Continuous variables were indicated by median and quartile variables. The number of regimens and gender are shown in Table 1. A chi-square test analysis was used to compare the characteristics of patients. For normality of distribution of continuous variables, the Kolmogorov-Smirnov test was used. Log-rank analyses using the Kaplan-Meier method were conducted to assess whether hypothyroidism was associated with either progression-free survival (PFS) or OS. In this study, the factors judged to be clinically important were taken as model variables. A Cox proportional hazards model that considered hypothyroidism was used to estimate the hazard ratios (HRs) for PFS and OS, with the first onset of hypothyroidism obtained in the hospital treated as a time-dependent covariate. It was analyzed in the Cox proportional model to identify independent variables predicting PFS or OS extension. Twosided $p$ values less than 0.05 were considered significant. Based on previous studies, we assumed that a survival difference of around $35 \%$ will be obtained. For 34 patients (17 patients per group), the study would have $80 \%$ power with a type 1 error of $5 \%$. All analyses were performed using BellCurve for Excel (Social Survey Research Information Co., Ltd.).

\section{Results}

\section{Patient Characteristics}

The patient characteristics are summarized in Table 1. In total, 50 patients received axitinib treatment. Of them, 44 patients received axitinib as secondary or later treatment. The number of patients with and without hypothyroidism was 30 and 14, respectively. The average age of patients with and without hypothyroidism was 67.3 and 66.4 years, respectively, with no significant difference between the 2 groups (Table 2). Thirty-nine patients (89\%) 
Table 2. Number of patients with and without hypothyroidism receiving axitinib treatment

\begin{tabular}{llll}
\hline Characteristic & \multicolumn{2}{l}{ Number of patients } & $P$ value \\
\cline { 2 - 3 } & hypothyroidism $(n=31)$ & nonhypothyroidism $(n=13)$ \\
\hline Age, years, median (IQR) & $67(65-73)$ & $68(63-74)$ & $10 / 4$ \\
Gender, male/female & $19 / 11$ & $13 / 2 / 0$ & 0.7 \\
Prior number of chemotherapy regimen & $20 / 6 / 3$ & 0.74 \\
\hline
\end{tabular}

IQR, interquartile range.

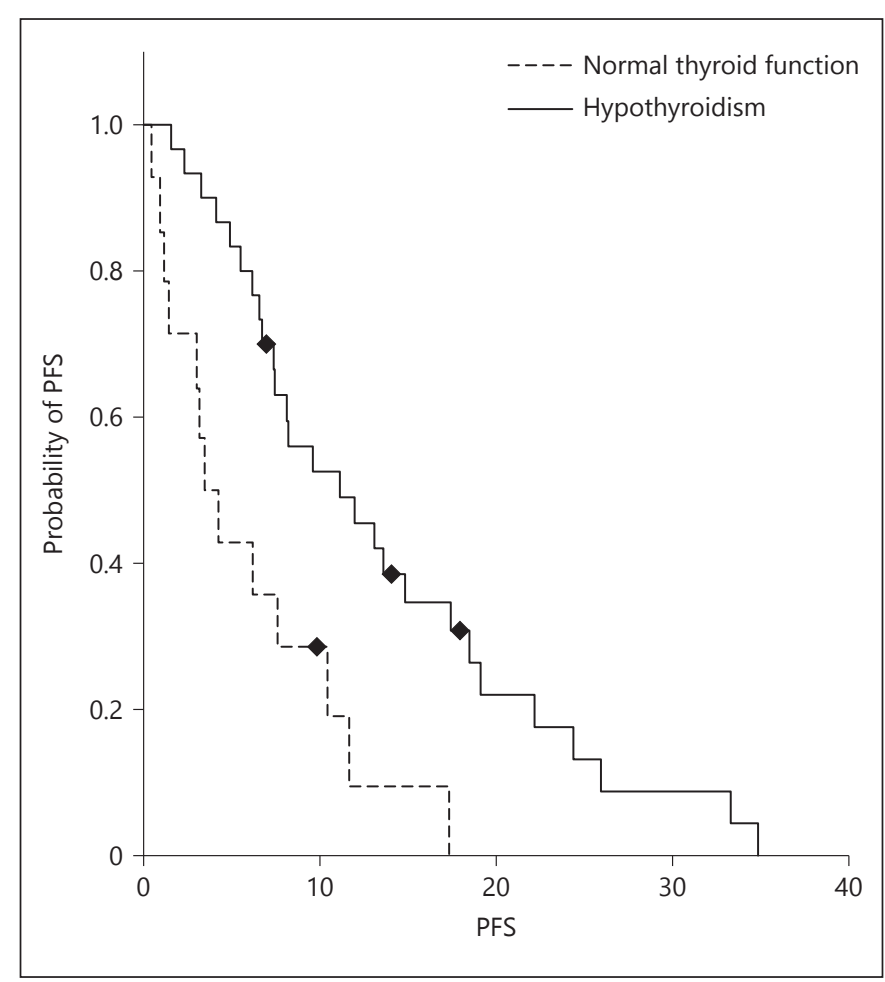

Fig. 1. Kaplan-Meier curves of hypothyroidism and normal thyroid function for progression-free survival.

discontinued axitinib therapy: 5 patients (11\%) discontinued because of treatment-related adverse events and $34(77 \%)$ discontinued because of disease progression. As of the end date of this analysis (31/8/2018), 5 patients (11\%) received axitinib.

\section{Safety and Efficacy}

Treatment-related adverse effects were hypertension $(81 \%)$, proteinuria (56\%), hypothyroidism $(68 \%)$, handfoot-syndrome (41\%), diarrhea (33\%), and oral mucositis $(30 \%)$.

Axitinib-Induced Hypothyroidism is a

Predictive Marker for the Survival

\section{Relationship between Hypothyroidism and} $P F S$ and $O S$

The median OS was significantly longer in the hypothyroidism group than in the normal thyroid function group (26.4 vs. 15.6 months, HR 0.38 [95\% CI 0.17-0.85], $p=0.02$; Fig. 1). The median PFS was significantly longer in the hypothyroidism group than in the normal thyroid function group (11.5 vs. 3.5 months, $\mathrm{HR}=0.34$ [95\% CI $0.16-0.70], p=0.003$; Fig. 2 ).

\section{Cumulative Onset of Hypothyroidism during}

Axitinib Treatment

The cumulative incidence of hypothyroidism was approximately 180 days. The incidence of hypothyroidism was $68 \%$ (Fig. 3 ).

\section{Discussion}

In this study, we aimed to establish an effective predictor of axitinib treatment. We selected hypothyroidism as a predictor. PFS and OS were prolonged in the thyroid dysfunction group compared to that in the thyroid function normal group.

Hypertension is a well-known side effect contributing to the outcome of axitinib and sunitinib treatment $[9,10$, 11]. Rini et al. [9] reported that sunitinib-induced hypertensive group significantly prolonged PFS and OS compared to nonhypertensive group. Patients with maximum systolic blood pressure of at least $140 \mathrm{~mm} \mathrm{Hg}$ had better outcomes than those without treatment-induced hypertension (median PFS: 12.5 vs. 2.5 months; OS: 30.9 vs. 7.2 months, $p<0.001$ for all). Rini et al. [10] indicated that patients with diastolic blood pressure $>90 \mathrm{~mm} \mathrm{Hg}$ had a significantly lower risk of death than those with diastolic blood pressure $<90 \mathrm{~mm} \mathrm{Hg}$ (PFS: 10.2 vs. 7.1 months, OS: 25.8 vs. 14.9 months), suggesting that diastolic hypertension correlates with clinical outcome. In 


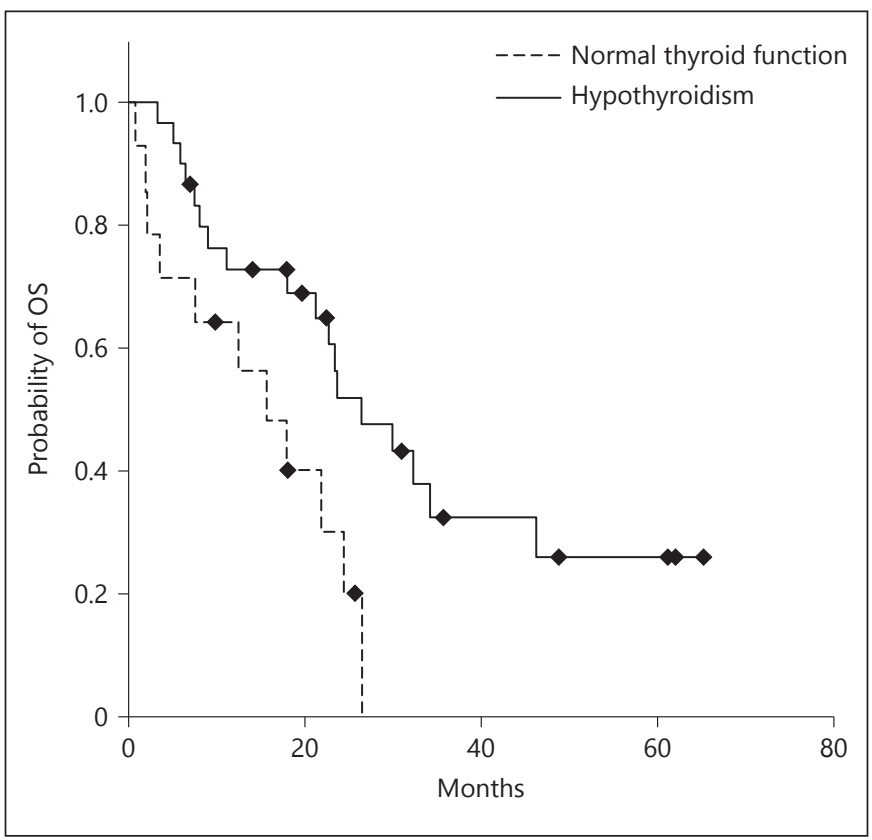

Fig. 2. Kaplan-Meier curves of hypothyroidism and normal thyroid function for overall survival.

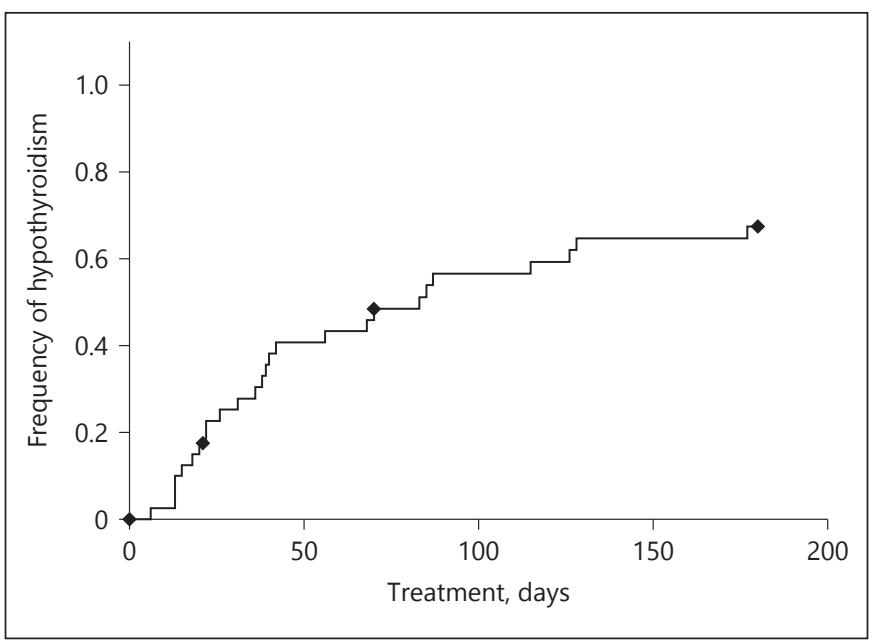

Fig. 3. Frequency and onset of hypothyroidism during axitinib treatment $(n=44)$.

addition, onset of hypothyroidism in sunitinib treatment has been reported as an indicator of therapeutic effect $[12,13]$. From the above findings, hypertension can be suggested as a biomarker for PFS and OS prolongation in axitinib and sunitinib treatment. In addition, hypothyroidism is a biomarker for PFS prolongation in sunitinib treatment. However, the relationship between hy- pothyroidism and prolongation of PFS in axitinib treatment has not been reported. In our retrospective study, the relationship between hypothyroidism/normal thyroid function and therapeutic effects (PFS and OS) was examined. Previous studies have shown that VEGFR-TKI can be a useful marker for side effects related to VEGFR inhibition, which is in agreement with our study results. In our study, comparison of presence and absence of hypothyroidism in axitinib treatment showed significantly improved clinical outcome (PFS; 11.1 vs. 4.2 months, OS; 26.4 vs. 15.6 months; Fig. 1, 2). Our findings showed that hypothyroidism is significantly associated with clinical effects in patients treated with axitinib as a secondary treatment for mRCC. Previous studies reported that the frequency of hypothyroidism associated with axitinib was $20-89 \%$ [14, 15]. In phase III trial (AXIS), thyroid function reduction rate was $21 \%$ for axitinib and $7 \%$ for sorafenib. In contrast, Japanese subanalysis showed that hypothyroidism incidence was higher with axitinib (44\%) than with sorafenib (24\%). In a phase I/II trial, up to $89 \%$ patients showed increased TSH level [15]. Another study reported that the risk of hypothyroidism was higher for axitinib than for sorafenib and sunitinib (HR $4.53, p=0.01$ ) [16]. As the frequency and timing of hypothyroidism may differ for each TKI, TKIs should be considered individually. Even with the same TKI, the frequency of hypothyroidism may show racial differences. Therefore, racial differences are considered meaningful in the study of Japanese who are frequently diagnosed with axitinib-induced hypothyroidism. Hypothyroidism is reported to occur within 6 months of axitinib treatment [17]. In our study, 6 months was taken as the object of observation, considering the onset time of hypothyroidism. The frequency of hypothyroidism is thought to be dependent on the follow-up duration during axitinib treatment and cutoff value of TSH. TSH was elevated in $70 \%$ of patients receiving sunitinib [18]. Sufficient diagnosis cannot be made without checking clinical symptoms (e.g., fatigue) because of differences in TSH facility standards. Expert groups such as the American Thyroid Association and the American Association of Clinical Endocrinologists recommend thyroid hormone treatment to be initiated whenever TSH increases above 10 $\mu \mathrm{IU} / \mathrm{mL}$ [19]. TSH elevated by thyroid dysfunction is known to be reversible. In the case of sunitinib, TSH is normalized during the off period; therefore, for monitoring hypothyroidism, OFF period is recommended. Because axitinib has no OFF period, periodic confirmation is necessary [13]. TSH value can be considered a potential marker of hypothyroidism in routine clinical setting. 
To avoid dose reduction and discontinuation of axitinib, thyroid function should be regularly monitored, and levothyroxine should be started when hypothyroidism is confirmed. Levothyroxine use has not been found to be associated with survival [11].

There are certain limitations to our study. First, this was a retrospective study. Second, although TSH values at the beginning of axitinib treatment were available, the effect of TKI primary treatment on thyroid function cannot be completely excluded. Therefore, the definition of hypothyroidism is more complicated than that for primary treatment of TKI. In this study, patients who already had elevated TSH at the beginning of axitinib treatment were defined as having a re-elevation of TSH and hypothyroidism. Alternatively, patients taking levothyroxine at the start of axitinib treatment were defined as having reincreased levothyroxine and hypothyroidism. Third, because the sample size was small, studies using larger cohorts are warranted. Fourth, as this is a single center study, results cannot be generalized to different populations.

In conclusion, hypothyroidism associated with axitinib significantly increased PFS and OS. Early detection and early response to hypothyroidism are important factors for the continuation of axitinib therapy. We believe that regular monitoring of thyroid function is necessary for continuing effective treatment with axitinib.

\section{Acknowledgments}

I would like to express my gratitude to all the researchers of Hokkaido Cancer Center who participated in this study. I would especially like to thank Mr. Nagamori for his detailed advice.

\section{Statement of Ethics}

This study was approved by the Ethics Committee of Hokkaido Cancer Center (Approval No: 30-86). All patients provided written informed consent to participate in the study.

\section{Disclosure Statement}

The authors have no conflicts of interest to declare.

\section{Funding Source}

This research did not receive any supporting funding.

\section{Author Contributions}

All authors discussed the results and commented on the manuscript. S.N.: confirmed medical judgment and designed this study. H.H.: provided advice on statistical analysis. E.M.: edited the manuscript.

\section{References}

1 Escudier B, Albiges L, Sonpavde G. Optimal management of metastaticrenal cell carcinoma: current status. Drugs. 2013 Apr;73(5):427-38.

2 Hu-Lowe DD, Zou HY, Grazzini ML, Hallin ME, Wickman GR, Amundson K, et al. Nonclinical antiangiogenesis and antitumor activities of axitinib (AG-013736), an oral, potent, and selective inhibitor of vascular endothelial growth factor receptor tyrosine kinases 1, 2, 3 . Clin Cancer Res. 2008 Nov; 14(22):7272-83.

3 Rini BI, Escudier B, Tomczak P, Kaprin A, Szczylik C, Hutson TE, et al. Comparative effectiveness of axitinib versus sorafenib in advanced renal cell carcinoma (AXIS): a randomised phase 3 trial. Lancet. 2011 Dec;378(9807):1931-9.

4 Escudier B, Pluzanska A, Koralewski P, Ravaud A, Bracarda S, Szczylik C, et al.; AVOREN Trial investigators. Bevacizumab plus interferon alfa-2a for treatment of metastatic renal cell carcinoma: a randomised, double-blind phase III trial. Lancet. 2007 Dec;370(9605):2103-11.

5 Rini BI, Halabi S, Rosenberg JE, Stadler WM, Vaena DA, Ou SS, et al. Bevacizumab plus interferon alfa compared with interferon alfa monotherapy in patients with metastatic re- nal cell carcinoma: CALGB 90206. J Clin Oncol. 2008 Nov;26(33):5422-8.

6 Escudier B, Eisen T, Stadler WM, Szczylik C, Oudard S, Siebels M, et al.; TARGET Study Group. Sorafenib in advanced clear-cell renal-cell carcinoma. N Engl J Med. 2007 Jan; 356(2):125-34.

7 Motzer RJ, Hutson TE, Tomczak P, Michaelson MD, Bukowski RM, Rixe O, et al. Sunitinib versus interferon alfa in metastatic renal-cell carcinoma. N Engl J Med. 2007 Jan; 356(2):115-24.

8 Sternberg CN, Davis ID, Mardiak J, Szczylik C, Lee E, Wagstaff J, et al. Pazopanib in locally advanced or metastatic renal cell carcinoma: results of a randomized phase III trial. J Clin Oncol. 2010 Feb;28(6):1061-8.

9 Rini BI, Cohen DP, Lu DR, Chen I, Hariharan $\mathrm{S}$, Gore ME, et al. Hypertension as a biomarker of efficacy in patients with metastatic renal cell carcinoma treated with sunitinib. J Natl Cancer Inst. 2011 May;103(9):763-73.

10 Rini BI, Schiller JH, Fruehauf JP, Cohen EE, Tarazi JC, Rosbrook B, et al. Diastolic blood pressure as a biomarker of axitinib efficacy in solid tumors. Clin Cancer Res. 2011 Jun; 17(11):3841-9.

11 Riesenbeck LM, Bierer S, Hoffmeister I, Köpke T, Papavassilis P, Hertle L, et al. Hypothyroidism correlates with a better prognosis in metastatic renal cancer patients treated with sorafenib or sunitinib. World J Urol. 2011 Dec;29(6):807-13.

12 Wolter P, Stefan C, Decallonne B, Dumez H, Bex M, Carmeliet P, et al. The clinical implications of sunitinib-induced hypothyroidism: a prospective evaluation. Br J Cancer. 2008 Aug;99(3):448-54.

13 Kust D, Prpić M, Murgić J, Jazvić M, Jakšić B, Krilić $\mathrm{D}$, et al. Hypothyroidism as a predictive clinical marker of better treatment response to sunitinib therapy. Anticancer Res. 2014 Jun;34(6):3177-84.

14 Motzer RJ, Escudier B, Tomczak P, Hutson TE, Michaelson MD, Negrier S, et al. Axitinib versus sorafenib as second-line treatment for advanced renal cell carcinoma: overall survival analysis and updated results from a randomised phase 3 trial. Lancet Oncol. 2013 May;14(6):552-62.
Axitinib-Induced Hypothyroidism is a Predictive Marker for the Survival
Urol Int 2019;102:435-440

DOI: $10.1159 / 000499089$ 
15 Kust D, Prpić M, Kruljac I, Bolanča A, Kusić Z. Tyrosine kinase inhibitors and hypothyroidism - an intriguing link. Endocr Oncol Metab. 2016 Jun;2(2):102-13.

16 Daimon M, Kato T, Kaino W, Takase K, Karasawa S, Wada K, et al. Thyroid dysfunction in patients treated with tyrosine kinase inhibitors, sunitinib, sorafenib and axitinib, for metastatic renal cell carcinoma. Jpn J Clin Oncol. 2012 Aug;42(8):742-7.
17 Lechner MG, Vyas CM, Hamnvik OR, Alexander EK, Larsen PR, Choueiri TK, et al. Risk Factors for New Hypothyroidism During Tyrosine Kinase Inhibitor Therapy in Advanced Nonthyroidal Cancer Patients. Thyroid. 2018 Apr;28(4):437-44.
18 Rini BI, Tamaskar I, Shaheen P, Salas R, Garcia J, Wood L, et al. Hypothyroidism in patients with metastatic renal cell carcinoma treated with sunitinib. J Natl Cancer Inst. 2007 Jan;99(1):81-3.

19 Torino F, Barnabei A, Paragliola R, Baldelli R, Appetecchia M, CorselloSM. Thyroid dysfunction as an unintended side effect of anticancer drugs. Thyroid. 2013 Nov;23(11):1345-66. 